\title{
La imagen de los políticos húngaros en la España contemporánea (1859-1866)
}

\section{Andrea Palkovics}

Repasando los mil años de las relaciones húngaro-españolas podemos ver que, después de ciertos períodos de intensas relaciones venían etapas más o menos largas cuando los dos países se alejaban uno del otro. En la España de la primera mitad del siglo XIX Hungría se consideraba una provincia del Imperio Habsburgo. En esta época las guerras carlistas representaban una ruptura en la relación de España con Austria (y los estados alemanes), ${ }^{1}$ pero, como para España este era el territorio adecuado para buscar aliados con el objetivo de disminuir su dependencia de la política exterior franco-inglesa, para 1848 las relaciones diplomáticas se habían reorganizado. ${ }^{2}$

Durante la guerra de independencia entre 1848 y 1849 para Europa Hungría dejó de ser una provincia del Imperio Habsburgo y gozaba de una atención particular por todo el continente, así que la prensa española también informaba con cierta regularidad acerca de sus acontecimientos. ${ }^{3}$

A continuación quisiera presentar qué imagen se formó en España acerca de los políticos húngaros de la época anterior a la Conciliación de 1867. Examinaré, por una parte, la imagen que tendría sobre los políticos húngaros la dirección política a través del aparato de política exterior que trataba los despachos enviados por los legados españoles de Viena ${ }^{4}$ y, por otra, la gente normal y corriente, que recibía sus informaciones de la prensa.

La misión de Viena fue dirigida desde 1858 hasta 1868 por Luis López de la Torre Ayllon, ${ }^{5}$ uno de los participantes más constantes y prestigiosos de las relaciones hispano-austríacas. Este diplomático era considerado gran conocedor de los asuntos austríacos y alemanes, además de sus estaciones en Baviera y otros principados alemanes, pasó mucho tiempo en Viena y hablaba muy bien alemán (lo cual era una gran ventaja en la diplomacia española de la época) y conocía personalmente a los participantes importantes de la vida política vienesa, así que sus informaciones proceden de los círculos oficiales de Viena y su punto de vista es semejante al de éstos. Al leer sus despachos, podemos descubrir cuáles eran las fuentes de sus informaciones: intentó asistir personalmente a los eventos importantes, leía con regularidad los diarios de Viena, con atención especial al Wiener Zeitung, en que aparecían con regularidad informaciones semi-oficiales sobre los debates parlamentarios, los asuntos del Consejo Imperial, y los cambios de personal ocurridos en los puestos estatales; además, una parte de sus informaciones la conseguía através de conversaciones con políticos. Desde el punto de vista de los asuntos húngaros es importante que el legado siempre se encontraba en Viena -Ayllon sólo asistió oficialmente a un evento celebrado en Hungría en ocasión de la coronación de Francisco José-, así que sus informaciones proceden de los círculos oficiales de Viena y su punto de vista es semejante al de éstos.

Los despachos no contienen descripciones detalladas sobre los políticos, y las pocas observaciones breves sólo aparecen cuando un nuevo político llega a un cargo o bien, como en el caso de István Széchenyi y Sámuel Jósika, cuando se informa acerca de su muerte. Generalmente podemos construir unos mosaicos pequeños basándonos en algunas de estas observaciones cortas.

Al repasar las informaciones ofrecidas por los despachos sobre los políticos húngaros podemos descubrir interesantes desproporciones. La sede de la legación de Viena naturalmente disponía de más informaciones sobre aquellos políticos que vivían en Viena o por lo menos pasaban mucho tiempo allí. Así en los despachos encontramos más informaciones sobre el partido de los antiguos conservadores y

\footnotetext{
${ }^{1}$ Ádám ANDERLE, "El carlismo y la Corte de Viena”, in: Acta Hispanica III, Szeged, 1998, 5-11.

2 Ádám ANDERLE (ed.), A magyar kérdés spanyol követi jelentések Bécsből 1848-1868, Szeged, Hispánia, 2002.

3 Ádám ANDERLE-Krisztina BABOS-Anita ILLIKMANN, “A magyar szabadságharc spanyol megítélése (1849 március-október)", in: Aetas 2000, 1-2, 249-275.

${ }^{4}$ Los documentos de la legación española de Viena referentes a este período se encuentran en el Archivo General del Ministerio de Asuntos Exteriores en los legajos n 1363, 1364, 1365 y 1366. A continuación en las referencias se indicarán el número del despacho y la fecha de su nacimiento.

${ }^{5}$ Acerca de él véase ANDERLE, op. cit., 238-239.
} 
los políticos pertenecientes a éste. Cuando en abril de 1860 informa sobre las muertes de Sámuel Jósika y Széchenyi la imagen de Jósika es positiva:

"Hombre conciliador el primero, de ideas conservadoras y conocimientos prácticos en la administracion de su pais, generalmente estimado en esta sociedad por la integridad de su caracter y sus amables prendas y amigo particular de muchos años del actual Ministro Presidente Conde Rechberg, considerabasele apesar de su patriótica oposicion al Gobierno Imperial como el natural medianero entre las necesidades políticas de este y las exageradas pretensiones de los Magnates Hungaros."

En la comparación de los dos políticos parece que Ayllon considera que la muerte de Jósika es una verdadera pérdida desde el punto de vista del acuerdo austro-húngaro, mientras que la de Széchenyi incluso puede tener como consecuencia graves demostraciones en Hungría:

"Así pues no será la muerte del Conde Széchenyi una pérdida para el Gobierno Imperial como lo es la muerte del Baron Jósika, porque al primero nunca hubiera logrado traerle á partido aun prescindiendo de su problemático estado mental; nunca hubiera logrado satisfacer su indomable vanidad Magyar, ni ganarse la voluntad de un hombre que se complacía en el papel de martir de la patria." 7

A continuación aparecen varias figuras de políticos húngaros en los despachos. El primer político es el conde György Apponyi, de quien al principio habla negativamente porque en el Consejo Imperial era el primer representante del caso húngaro y partidario del principio federalista. Más tarde se modera esta opinión acerca de él porque como Judex Curiae ya Ayllon destaca su papel de reconciliador:

"No provocó desde luego el discurso inaugural del Iudex-Curiae las demostraciones hostiles que eran de temer por parte de la aristocracia; ni era facil que las provocase, andando el Orador como sobre brasas al tocar cualquiera de las cuestiones candentes del dia y no insistiendo mas que en las esperanzas y deseos del Monarca de conciliarlo todo constitucionalmente con la nacion, razon por la cual me sería verdaderamente imposible analizar este discurso, si su mas que probable reproduccion en todos los diarios franceses no me dispensase de semejante trabajo. ",

Los otros políticos, Antal Szécsen y Miklós Vay también tenían cargos importantes: el primero era ministro del gobierno imperial, el segundo canciller. Ayllon no ofrece un retrato detallado de ellos tampoco pero parece que estaba bien informado en relación con sus planes: en su despacho del 20 de junio de 1861, basándose en informaciones procedentes del conde Szécsen, menciona que se planea la disolución de la dieta y la introducción de una gobernación dictatorial:

"Que medidas tomarán en seguida los Ministros para hacer respetar la autoridad Real en Hungría, no lo sé con alguna certeza. Tengo solo entendido, con referencia á ciertas manifestaciones confidenciales del Ministros Conde Szecsen, que se empezará por disolver la Dieta, luego se procurará establecer una Dictadura, compuesta toda ella de personages del país, para gobernarle en nombre del Rey; y, segun se manifieste propicia la opinion en los Condados, que en realidad no son mas que pequeñas Repúblicas independientes casi en todo de la misma autoridad central del Reino, emprenderá en ellos el Gobierno elecciones directas para el Consejo del Imperio. ""

En 1865 escribe en relación con el canciller Mailáth que éste político dispone de las cualidades más excelentes de un hombre de estado. ${ }^{10}$

Después de la inauguración del parlamento en 1861 aparecen en los despachos nombres de políticos del Partido del Mensaje y del Partido de la Resolución, pero sólo con algunas informaciones en pocas palabras:

"Sábese por lo demas que en ella va á ser la lucha entre los partidarios de Deák y Eötvös y los del Conde Ladislao Teleky y de Nyáry, lucha de la cual para formar alguna idea conviene recordar que Deák y Eötvös son los Jefes del antiguo partido liberal, que Teleky, el ex-Representante Diplomático de Kossuth en París y actual confidente del Príncipe Napoleon es el mismo sugeto tan generosa como

\footnotetext{
${ }^{6}$ Despacho no. 68, del 9 de abril de 1860.

${ }^{7}$ Idem.

${ }^{8}$ Despacho no. 62, del 11 de abril de 1861.

${ }^{9}$ Despacho no. 103, del 20 de junio de 1861.

${ }^{10}$ Despacho no. 184, del 19 de diciembre de 1865.
} 
inutilmente perdonado despues de su arresto en Dresde por S. M. Francisco José, y Nyáry, el mas exaltado Jefe de la asamblea Comital de Pest. ",l

El legado en este período no da informaciones ni siquiera de Ferenc Deák, lo que se puede explicar con que él mismo tampoco tenía datos exactos. Más tarde, después de 1865, como avanzan las negociaciones, ofrece cada vez más informaciones de Deák. En marzo de 1866 lo describe como una persona convertida realmente en el líder del parlamento húngaro, pero caracterizada más bien por rasgos de abogado en vez de por rasgos de hombre de política. ${ }^{12}$ Sin embargo reconoce que para poder realizar su tarea está dispuesto a renunciar a su popularidad.

"Por lo que toca al abogado Deák, dificil me sería designar en concreto los fines á que se dirige su pensamiento. Resabios revolucionarios se advierten de cuando en cuando en sus discursos. [...] Pero de su desinterés no hay que dudar, ni hoy tampoco de la lealtad monárquica y consecuencia con que lleva adelante el programa combinado con los Ministros cisleithanos y transleithanos [...]. Hasta va gastando Deák en tan árdua tarea lo que mas pareció apreciar en toda su vida política, su incontestable popularidad. ",3

También presenta a los miembros del gobierno responsable húngaro de forma general porque no los conoce personalmente:

"Todos ó los mas de esos Ministros pasan por cumplidos Caballeros, distinguidos oradores y hombres de particular talento en sus respectivas ramas; pero dudo, lo confieso, alcancen la fama de buenos Administradores en un pais tan desordenado como hoy dia el Reino de San Esteban."14

Finalmente hay que mencionar aquellas breves descripciones que hace el legado cuando se trata de un cambio de persona ocurrido en un puesto importante. En estos casos generalmente encontramos presentaciones breves, limitadas a comunicar los datos importantes. Sólo hay una excepción, cuando el legado presenta a Móricz Eszterházy, colocado al puesto de Antal Szécsen, precisamente a causa de su carrera diplomática:

"Creo que sucede lo mismo en punto á su lengua materna al Conde Eszterházy, ${ }^{15}$ el mismo que desempeñó por algunos años la Embajada de Austria en Roma y á quien tuvo al fin que separar el Sr. Conde de Buol por no haber sido posible arrancarle en mas de seis meses, apesar de su incontestable talento, un solo renglon de correspondencia Diplomática. Confieso que por mi parte nunca hubiese creido ver a un hombre tan amigo de sus conveniencias y desidioso en el cumplimiento de sus deberes admitir el cargo de Ministro en las críticas circunstancias del dia, y si lo ha hecho solo puede haberle ${ }_{16}$ movido su vehemente deseo de volver á su antigua carrera, porque bienes de fortuna tiene de sobra."

El reinado de Isabel II se caracterizaba no sólo por la inseguridad de la política interior, y el ejército cada vez más activo en la política, sino también por el desarrollo dinámico de la economía. La construcción de las vías férreas fue una innovación revolucionaria en el transporte (durante estos años fueron construidos aproximadamente 60 mil kilómetros de ferrocarriles). Al mismo tiempo, la prensa llegaba a dirigir la opinión pública. Desde luego, al examinar el papel de la prensa, no se debe olvidar que en 1860 el 85 por 100 de la población adulta masculina era analfabeta. ${ }^{17}$ Para los demás los diarios eran asequibles no sólo a través de la venta en la calle: también los vendían las salas de lectura de las cafeterías y asociaciones que incluso tenían suscripción. En los años 50 y 60 el número de diarios superaba los 50 pero sólo una parte de ellos podía contar con una esperanza de vida más larga. Entonces aparecieron los primeros periódicos informativos. Los diarios alcanzaban una tirada de 10 mil ejemplares aproximadamente. Destacaba Las Novedades con una tirada de 30 mil ejemplares. (A modo de comparación: The Times y Le Siècle se editaban con unos 40 mil ejemplares diarios. $)^{18}$ La orientación política de los diarios se distinge marcadamente. Vamos a mencionar sólo algunos

\footnotetext{
${ }^{11}$ Despacho no. 62, del 11 de abril de 1861.

${ }^{12}$ Despacho no. 49, del 22 de marzo de 1866.

${ }^{13}$ Despacho no. 87, del 8 de mayo de 1867.

${ }^{14}$ Despacho no. 40, del 28 de febrero de 1867.

${ }^{15}$ Antal Forgách fue nombrado canciller al mismo tiempo; Ayllon menciona en relación con ambos que apenas hablaban húngaro.

${ }^{16}$ Despacho no. 125, del 21 de julio de 1861.

${ }^{17}$ Fernando GARCÍA DE CORTÁZAR, José Manuel GONZÁLEZ VESGA, Breve historia de España, Madrid, Alianza Editorial 1994, 444.

${ }^{18}$ Miryam SÁNCHEZ PRIETO, Historia de la prensa en España, Szeged, Hispánia, 2000, 51.
} 
ejemplos: diarios ministeriales - El Clamor Público, El Diario Español, El Día, El Occidente; liberales - Las Novedades, La España, El Horizonte; progresista - La Iberia; demócrata - La Discusión; moderado - El Reino; conservador-neocatólicos - La Regeneración, El Pensamiento Español.

Las noticias de los diarios españoles de la época procedían de diferentes fuentes. Ya existían agencias telegráficas de informaciones que informaban a la prensa española acerca de las noticias extranjeras (como la Agencia Havas) así como de las noticias de política interior (como la Agencia Peninsular). Estas noticias aparecían en la mayoría de los diarios de forma textualmente idéntica. La diferencia de tiempo que existía entre los acontecimientos y su aparición en la prensa era de 2 a 4 días. Además de estas cosas, también divulgaban comentarios publicados en los diarios extranjeros (ingleses, alemanes, franceses) más importantes.

Al buscar noticias referentes a acontecimientos relacionados con Hungría en los diarios españoles de los años 60, nuestra primera observación es la siguiente: hay períodos cuando cada semana, a veces cada día, aparecen noticias referentes a Hungría, pero en otros períodos no se puede leer nada de este tema. ${ }^{19}$ Parece que entre las noticias extranjeras las noticias húngaras se encontraban en segundo plano, y sólo se les concedía más espacio cuando en el resto de Europa o en los territorios ultramarinos no sucedía nada que mereciera más atención. Así por ejemplo los lectores españoles disponían de abundantes informaciones relacionadas con las sesiones de la dieta húngara de 1861, pero las noticias referentes a los preparativos de la conciliación fueron sustituidos por las novedades de la guerra civil norteamericana y de la guerra entre Prusia y Austria.

¿Quiénes eran los políticos húngaros cuyos nombres conocían los lectores españoles? La prensa siempre informaba acerca de la muerte de los políticos importantes: por ejemplo, después del suicidio de László Teleki ${ }^{20}$ en Las Novedades aparece una biografía detallada de él, basada en Wanderer. ${ }^{21}$

Además de los informes breves, se pueden leer con frecuencia traducciones de decretos y leyes, así que los nombres de los políticos que ocupaban cargos importantes podían ser familiares a los lectores. Durante la dieta de 1861 incluso se publicaron cortos resúmenes de los discursos, así también los nombres de los oradores principales aparecen varias veces en la prensa. El nombre más frecuente que surge en los diarios es el de Ferenc Deák. Naturalmente el carácter de los diarios no permite que se presenten retratos de políticos, pero en el caso de Deák se ofrecen algunas informaciones al lector. Éste puede ver el entusiasmo que incitaban sus discursos en el parlamento ("Dicho discurso [se refiere al discurso de Deák del 13 de mayo] ha producido en la Asamblea profunda sensacion. Fue frecuentemente interrumpido por ruidos aplausos."), ${ }^{22}$ y también lo difícil que era su tarea de mantener el equilibrio entre los diferentes partidos: "La Cámara parecia resuelta a tomar algunas disposiciones interiores que indicarían un espiritu de hostilidad bastante marcado, pero Deack consiguió atraerla a la contemporizacion y a la prudencia". ${ }^{23}$

A modo de conclusión podemos afirmar lo siguiente en relación con la imagen que tenían los políticos húngaros en España.

Aunque Hungría no se encontraba entre los territorios más interesantes para la gente contemporánea en España, hasta los lectores de los diarios podían conocer los nombres de los políticos húngaros más importantes. Por otra parte, sin embargo, los miembros del aparato de Asuntos Exteriores, que conocían los despachos de los legados, sólo disponían de algunas informaciones más detalladas relacionadas con los personajes de la política. En cuanto a las informaciones que ofrecen los despachos, se puede observar cierta desproporción respecto a su contenido y a la realidad de la política húngara: los legados tenían más informaciones sobre los políticos cercanos a Viena, los cuales, sin embargo, no eran necesariamente los que tenían mayor peso en el desarrollo de los asuntos políticos en Hungría. En la prensa esta desproporción no aparece debido a que en los diarios sólo aparecen los nombres de los políticos en las noticias - más cortas por su naturaleza que los despachos oficiales. La única excepción es el caso de Deák, cuyo nombre se menciona con cierta frecuencia, pero ello

\footnotetext{
${ }^{19}$ Sobre este tema véase también Andrea PALKOVICS, "La dieta húngara de 1861 en la prensa española", in: Acta Hispanica VII, Szeged 2002, 47-57.

${ }^{20}$ László Teleki, líder del Partido de la Resolución se suicidó el día 8 de mayo de 1861.

${ }^{21}$ Las Novedades, 17 de mayo de 1861.

${ }^{22}$ El Pensamiento Español, 16 de mayo de 1861.

${ }^{23}$ Las Novedades, 17 de julio de 1861.
} 
corresponde a su peso verdadero y su papel importante que desempeñaba en la política húngara de entonces. 